\title{
Multimorbidity and tooth loss: the Brazilian National Health Survey, 2019
}

\author{
Rafael Aiello Bomfim ${ }^{1 *}$, Andreia Morales Cascaes ${ }^{2}$ and Cesar de Oliveira ${ }^{3}$
}

\begin{abstract}
Background: Little is known about the presence of two or more chronic conditions (multimorbidity) on tooth loss between adults and older adults. Understanding the mechanisms of multimorbidity on tooth loss is essential to inform policy development. This study aims to investigate the association between multimorbidity and severity of tooth loss in Brazilian adults and older adults.

Methods: We analysed data from a nationally representative sample of 88,531 Brazilian individuals aged 18 and over who participated in the 2019 Brazilian Health Survey. Tooth loss was the outcome by two different classifications: functional dentition (lost 1-12 teeth) and severe tooth loss (lost 23-32 teeth). The presence of multimorbidity was the main exposure and based on 13 self-reported doctor-diagnosed chronic diseases that were further categorised into two groups, i.e., $\geq 2$ or $\geq 3$ comorbidities. Sociodemographic covariates included sex, age, race, income, level of education and tobacco smoking and geographic region of residency. Multivariate logistic regression models estimated the OR (Odds Ratios) and $95 \% \mathrm{Cl}$ of the associations between multimorbidity and tooth loss.

Results: For 65,803 adults (aged 18 to 59 ), the presence of multimorbidity ( $\geq 2$ ) was associated with $32 \%$ higher odds of having severe tooth loss $(95 \% \mathrm{Cl}, 1.17 ; 1.49)$ and $33 \%$ lower odds of having functional dentition $(95 \% \mathrm{Cl}, 0.60 ; 0.75)$. For the 22,728 older adults (aged 60 and older), multimorbidity $(\geq 2)$ was associated with a 17\% higher odds of severe tooth loss $(95 \% \mathrm{Cl}, 1.06 ; 1.29)$ and $23 \%$ lower odds of having functional dentition ( $95 \% \mathrm{Cl} 0.70 ; 0.85)$. The sensitivity analysis, excluding hypertension, confirmed our findings.
\end{abstract}

Conclusions: Brazilian adults and older adults with multimorbidity are more likely to have severe tooth loss and less likely to have functional dentition.

Keywords: Multimorbidity, Tooth loss, Functional dentition, Severe tooth loss, Ageing, Oral health

\section{Background}

Tooth loss is an important public health concern for global health [1-3] that impacts peoples' quality of life [4]. In addition, there is increasing evidence that tooth loss could be associated with diet-related chronic diseases [5] such as malnutrition [6], obesity [7], cardiovascular diseases [8], hypertension [9], diabetes [10], certain types of cancer [11, 12], and, ultimately, mortality [13].

\footnotetext{
*Correspondence: aiello.rafael@gmail.com

${ }^{1}$ School of Dentistry, Federal University of Mato Grosso do Sul, Campo Grande, Brazil

Full list of author information is available at the end of the article
}

The World Health Organization (WHO) defines 20 as the minimum number of permanent teeth required for individuals to take part in social activities and achieve an adequate masticatory function [14]. This number is known as a functional dentition [15]. However, severe tooth loss, defined by fewer than 10 remaining teeth in the oral cavity [16], could impact one's quality of life in a more extensive way.

The oral microbiota may change with systemic diseases [17], which may contribute to tooth loss. Chronic diseases with increased inflammation are frequently linked to increased risk of periodontal disease [18], a stronger predictor of tooth loss. For example, rheumatoid arthritis 
is a systemic autoimmune disease characterised by chronic inflammation [19], leading to bone loss. Other chronic conditions such as dementia have already been associated with poorer oral health and increased tooth loss during the life course [20]. Traditionally, oral health research has focused on the impact of a single chronic condition on oral health. However, many people have multiple chronic conditions [21].

Multimorbidity is a significant health problem globally [22, 23], and it is increasing as a phenomenon of global ageing [23]. It is the simultaneous occurrence of health problems in the same person, usually operationalised by the occurrence of $\geq 2$ or $\geq 3$ chronic diseases [24, 25]. In the UK, one in four patients of primary health care users [26] and in the USA, 25\% of the adult population, have multiple chronic conditions [27]. One large Brazilian study in older adults showed that multimorbidity was prevalent in $70 \%$ of individuals and was more frequent in women, poorer individuals, lower education level, aged 80 and over, non-white, and former smokers [24]. Another study has shown the dependent association of multimorbidity and edentulism later in life [28]. People who suffer from multiple chronic conditions are considered "heavy" users of health services [23] which in turn has a significant financial impact on societies globally. As multimorbidity and tooth loss share the same common individual risk factors [29], it is crucial to establish whether it is associated with tooth loss in large national samples, independently of the social determinants of health and contextual covariates in both adults and older adults. Such investigation is needed because of the potential adverse effects of chronic diseases on oral health and to implement public health interventions to address general and oral health conditions mutually. A previous investigation of the Brazilian National Health Survey in 2013 has shown that among individuals aged 18 or older $11 \%$ have lost all teeth and $23 \%$ did not have 20 remaining teeth [30].

Therefore, the main objective of the present investigation was to assess whether the presence of multimorbidity is associated with tooth loss, i.e. functional dentition and severe tooth loss, independently of individual and contextual covariates. We analysed data from a large nationally representative sample of Brazilian adults and older adults.

\section{Methods}

The data analysed in this study came from the 2019 National Health Survey (Pesquisa Nacional de Saúde PNS), designed to have a nationally representative sample of the Brazilian population. The 2019 PNS is a cross-sectional household survey with a sampling process carried out in three stages. Using clustering sampling techniques, each stage selection was conducted using probability proportional to size, in which first municipalities were selected, followed by census tracts and, finally, their households. More detailed information on PNS's sampling procedures and inclusion criteria can be found elsewhere [31]. This study is based on participants who have answered the individual questionnaire, comprising 88,531 individuals aged 18 and older. The PNS data is freely available on the Brazilian Institute of Geography and Statistics (IBGE) website: https://www.ibge.gov.br/ estatisticas/downloads-estatisticas.html

\section{Tooth loss assessment}

Tooth loss was measured by asking: "Have you lost any of your permanent upper teeth?" Response options were 1) No; 2) Yes, I have lost (number) teeth; 3) Yes, I have lost all my upper teeth. The same question was asked for the lower permanent teeth. The 2019 Brazilian Health Survey considered complete dentition to be 32 teeth, 16 in the upper and 16 in the lower arch. Upper and lower self-reported tooth loss count was analysed classified into two levels of severity, regardless of the tooth position: 1 ) Functional dentition, defined as at least 20 permanent teeth present [32]; and 2) Severe tooth loss considered fewer than 10 remaining permanent teeth.

\section{Multimorbidity assessment}

Chronic diseases were assessed with the following Yes/ No questions: "Has a medical doctor ever told you that you have ...?". The chronic diseases investigated were: 1 ) hypertension, 2) diabetes, 3) depression, 4) back problems, 5) mental problems (schizophrenia, bipolar disorder, dementia and related), 6) asthma, 7) arthritis or rheumatism, 8) cancer, 9) heart problem, 10) stroke, 11) chronic obstructive pulmonary disease (COPD), 12) chronic kidney disease, and 13) work-related musculoskeletal disorder.

\section{Covariates}

The following covariates included were considered at the individual and contextual levels: gender (men or women); age was divided into $18-34,35-44$ and $45-59$ years for adults and 60-69, 70-79 and 80years and over for older adults; level of education was classified into formative years ( 0 to 8$)$ and formal education (8 or more years) for both adults and older adults. Officially named in Brazil as colour/race, the self-described race was assessed using five options according to the categories proposed by the Brazilian Institute of Geography and Statistics (IBGE): 1) white; 2) black; 3) yellow; 4) brown, and 5) indigenous. We further categorise this variable into white versus non-white. Self-reported smoking status was measured as those who never smoked and individuals who smoked 
in the past and/or are current smokers. The geographic region of residence (South, Southwest, Midwest, North, and Northwest) was the contextual covariate.

\section{Statistical analysis}

Data analysis was performed using the Stata software version 14.2 (StataCorp LP, College Station, United States) using the survey module that considers the effects of stratification and conglomeration in estimating indicators and their precision measures. Absolute and relative frequencies, with their respective 95\% confidence intervals $(95 \% \mathrm{CI})$, were calculated for all variables. Age-standardised estimates for functional dentition and severe tooth loss (including edentulous) were reported for each covariate. We opted not to stratify edentulous at another category because severe tooth loss (fewer than 10 teeth present in the mouth) is a global health problem [16]. Associations between multimorbidity and levels of tooth loss were assessed through crude and adjusted logistic regressions and by reporting the Odds Ratio (OR) and their 95\% confidence intervals. In addition, a sensitivity analysis excluding hypertension was performed. We followed the STROBE checklist for human observational studies [33]. All methods were performed in accordance with the relevant guidelines and regulations.

The Brazilian Committee approved the survey protocol on Ethics in Human Research (protocol number 3.529.376).

\section{Results}

Out of the 90,846 selected households, the analytical sample comprised of 65,803 participants aged 18-59 and 22,728 older adults (aged 60 and older) who had information on all variables included in the study. Table 1 shows the sample characteristics. The age-standardised estimates of having a functional dentition were higher among white participants, men, earning above one minimum wage, higher level of education, non-smokers, and those with no multimorbidity, for both adults and older adults.

Table 2 displays the prevalence and weighted proportions for all self-reported chronic diseases. For older adults, the three most prevalent chronic conditions were hypertension (56\%), back problems (31\%) and diabetes (21\%). For adults, the three most prevalent chronic conditions were back problems (19\%), hypertension (17\%) and depression $(9,8 \%)$. Concerning diseases combinations, $20 \%$ of older adults have hypertension and back problems, and $7,4 \%$ had hypertension, back problems and arthritis. For adults, 5,2\% had hypertension and back problems, and $1,5 \%$ had the combination of depression, back problems and hypertension.
Table 3 shows the odds ratios (OR) for older adults with multimorbidity ( $\geq 2$ or $\geq 3$ ) compared to their counterparts. We found that those with $\geq$ two chronic diseases had a $23 \%(95 \%$ CI 0.70 ; 0.85$)$ lower chance of having a functional dentition and $17 \%$ (95\% CI 1.06;1.29) higher chance of having severe tooth loss (including edentulous), independently of individual and contextual covariates, important area-level characteristics in the country. We found similar results for multimorbidity $\geq 3$. Our sensitivity analysis (Additional file 1: Appendix 1), excluding those individuals with hypertension, confirmed our findings and showed a similar pattern.

Table 4 showed the coefficients (OR) for adults with multimorbidity ( $\geq 2$ or $\geq 3$ ). We found that adults with multimorbidity $\geq 2$ chronic diseases had a $33 \%$ (95\% CI $0.60 ; 0.75)$ lower chance of having a functional dentition and a $32 \%(95 \%$ CI $1.17 ; 1.49)$ higher chance of severe tooth loss. We found similar results for multimorbidity $\geq 3$. Our sensitivity analysis (Additional file 1: Appendix 2), excluding those individuals with hypertension, confirmed our main findings.

\section{Discussion}

The main finding of this large nationally representative investigation is that multimorbidity was associated with tooth loss in both Brazilian adults and older adults. Furthermore, individuals with multimorbidity were less likely to have a functional dentition and had a higher risk of having severe tooth loss, independently of sociodemographic, behavioural and contextual covariates, highlighting the importance of monitoring the oral health of individuals with multimorbidity.

Traditionally, oral health research has focused on a single disease and its association with tooth loss, such as diabetes [34], hypertension [9] and cancer [12]. However, many people have several chronic diseases. Tooth loss is a complex measure in oral health epidemiology [2], and its occurrence at earlier stages of life could predict future tooth loss and negligent attitudes toward general health, favouring the presence of multimorbidity. Our findings showed that $50 \%$ of older adults and $20 \%$ of adults have multimorbidity, showing its importance as a public health issue. The prevalence of multimorbidity found in the present study is similar to other studies in older adults in China (45\%) and Ghana (48\%) [35]. Another Brazilian study in older adults has shown a prevalence of $70 \%$ of individuals with multimorbidity [24]. The explanation for this higher prevalence could be attributed to the inclusion of eyes diseases such as cataracts and high cholesterol [24].

Chronic diseases may change the oral microbiota [17], which in turn may contribute to tooth loss. In addition, multiple chronic diseases with increased inflammation 
Table 1 Descriptive characteristics and proportions of Brazilian adults and older-adults and age-standardised prevalence of tooth loss

\begin{tabular}{|c|c|c|c|c|c|c|c|c|c|}
\hline \multirow[t]{3}{*}{ Variables } & \multirow[t]{3}{*}{$n=65,803$} & \multirow[t]{3}{*}{$\%$} & $\begin{array}{l}\text { Presence of } \\
\text { Functional } \\
\text { dentition }^{b}\end{array}$ & \multicolumn{2}{|l|}{ Severe tooth loss ${ }^{b}$} & \multirow[t]{3}{*}{$n=22,728$} & \multirow[t]{3}{*}{$\%$} & \multirow{3}{*}{$\begin{array}{l}\text { Presence of } \\
\text { Functional } \\
\text { dentition }^{\mathrm{b}} \\
\%(95 \% \mathrm{Cl}) \\
\text { Older Adults }\end{array}$} & \multirow[t]{3}{*}{ Severe tooth loss ${ }^{b}$} \\
\hline & & & $\%(95 \% \mathrm{Cl})$ & $\%(95 \% \mathrm{Cl})$ & & & & & \\
\hline & & & \multicolumn{3}{|l|}{ Adults } & & & & \\
\hline \multicolumn{10}{|l|}{ Multimorbidity } \\
\hline No (one or zero) & 53,665 & 80.7 & $90.4(90.0 ; 90.9)$ & $5.0(4.7 ; 5.4)$ & & 11,748 & 49.1 & $26.3(24.3 ; 28.4)$ & $61.5(59.0 ; 63.9)$ \\
\hline $\begin{array}{l}\text { multimorbid- } \\
\text { ity } \geq 2\end{array}$ & 12,138 & 19.3 & $87.5(86.7 ; 88.2)$ & $6.5(5.9 ; 7.0)$ & & 10,980 & 50.9 & $20.4(18.7 ; 22.3)$ & $68.7(66.7 ; 70.7)$ \\
\hline \multicolumn{10}{|l|}{ Racial Groups } \\
\hline White & 22,508 & 41.3 & $91.4(90.8 ; 92.0)$ & $4.7(4.2 ; 5.2)$ & & 9901 & 50.5 & $27.8(25.5 ; 30.1)$ & $60.1(57.3 ; 62.9)$ \\
\hline Non-white ${ }^{a}$ & 43,295 & 58.7 & $88.0(87.5 ; 88.5)$ & $6.2(5.9 ; 6.6)$ & & 12,827 & 49.5 & $18.6(17.0 ; 20.3)$ & $70.3(68.2 ; 72.2)$ \\
\hline \multicolumn{10}{|l|}{ Sex } \\
\hline Female & 34,334 & 52.2 & $87.8(87.2 ; 88.4)$ & $6.6(6.2 ; 7.1)$ & & 12,535 & 56.7 & $20.5(18.8 ; 22.3)$ & $69.4(67.3 ; 71.4)$ \\
\hline Male & 31,469 & 47.8 & $91.4(90.9 ; 91.9)$ & $4.3(3.9 ; 4.6)$ & & 10,193 & 43.3 & $27.0(25.3 ; 28.7)$ & $59.4(57.1 ; 61.5)$ \\
\hline \multicolumn{10}{|l|}{ Per capita Income } \\
\hline $\begin{array}{l}<1 \text { minimum } \\
\text { wage }\end{array}$ & 38,046 & 53.8 & $85.4(84.8 ; 85.9)$ & $8.0(7.6 ; 8.5)$ & & 10,250 & 41.7 & $14.5(13.4 ; 15.6)$ & $75.2(73.5 ; 76.8)$ \\
\hline $\begin{array}{l}\geq 1 \text { minimum } \\
\text { wage }\end{array}$ & 27,738 & 46.2 & $93.3(92.8 ; 93.7)$ & $3.3(3.0 ; 3.6)$ & & 12,475 & 58.2 & $29.7(27.7 ; 31.7)$ & $57.9(55.3 ; 60.3)$ \\
\hline \multicolumn{10}{|l|}{ Schooling years } \\
\hline$<8$ years & 25,689 & 34.9 & $83.8(83.2 ; 84.4)$ & $8.7(8.2 ; 9.3)$ & & 16,414 & 70.1 & $16.6(15.4 ; 18.0)$ & $71.2(69.1 ; 73.2)$ \\
\hline$\geq 8$ years & 40,114 & 65.1 & $95.0(94.7 ; 95.2)$ & $2.2(1.9 ; 2.4)$ & & 6314 & 29.9 & $50.3(47.2 ; 50.3)$ & $38.9(36.0 ; 41.9)$ \\
\hline \multicolumn{10}{|c|}{ Geographic region } \\
\hline North & 13,610 & 8.3 & $87.3(86.5 ; 88.2)$ & $6.2(5.6 ; 6.8)$ & & 3487 & 6.1 & $17.4(15.4 ; 19.7)$ & $68.3(65.6 ; 70.8)$ \\
\hline Northwest & 22,966 & 26.8 & $85.2(84.5 ; 85.8)$ & $7.9(7.4 ; 8.4)$ & & 7736 & 25.4 & $17.7(16.1 ; 19.4)$ & $71.2(68.9 ; 73.4)$ \\
\hline Midwest & 7808 & 7.9 & $89.9(89.0 ; 90.7)$ & $5.6(4.9 ; 6.4)$ & & 2373 & 6.4 & $23.0(20.9 ; 25.2)$ & $66.8(64.3 ; 69.1)$ \\
\hline Southwest & 13,610 & 42.6 & $92.2(91.5 ; 92.8)$ & $4.2(3.7 ; 4.8)$ & & 5825 & 46.4 & $30.0(27.7 ; 32.4)$ & $58.6(56.0 ; 61.2)$ \\
\hline South & 7969 & 14.4 & $89.9(89.1 ; 90.7)$ & $4.9(4.4 ; 5.5)$ & & 3307 & 15.7 & $26.7(24.3 ; 29.3)$ & $58.0(55.2 ; 60.8)$ \\
\hline \multicolumn{10}{|l|}{ Smoking status } \\
\hline yes/in the past & 21,162 & 32.3 & $86.5(85.9 ; 87.1)$ & $7.4(6.9 ; 7.9)$ & & 11,117 & 50.3 & $20.9(19.4 ; 22.6)$ & $65.8(63.4 ; 67.3)$ \\
\hline never & 44,641 & 67.7 & $91.5(91.0 ; 92.0)$ & $4.2(3.8 ; 4.7)$ & & 11,611 & 49.7 & $24.8(23.1 ; 26.7)$ & $65.4(63.2 ; 68.3)$ \\
\hline \multicolumn{10}{|l|}{ Age Groups } \\
\hline $18-34$ & 24,115 & 40.8 & $99.4(99.2 ; 99.5)$ & $0.3(0.2 ; 0.4)$ & $60-69$ & 24,247 & 56.3 & $45.3(43.8 ; 46.8)$ & $38.4(36.9 ; 39.9)$ \\
\hline $35-44$ & 18,033 & 25.8 & $95.3(94.8 ; 95.8)$ & $1.7(1.5 ; 2.0)$ & $70-79$ & 13,209 & 30.1 & $28.0(26.3 ; 29.8)$ & $59.0(57.0 ; 61.0)$ \\
\hline $45-59$ & 23,655 & 33.4 & $74.4(73.4 ; 75.4)$ & $13.9(13.1 ; 14.8)$ & $80+$ & 6098 & 13.6 & $12.0(9.9 ; 14.6)$ & $78.5(74.9 ; 81.7)$ \\
\hline
\end{tabular}

${ }^{a}$ Brown/Black/Indigenous/Asian

${ }^{\mathrm{b}}$ Age-standardized

are frequently linked to increased risk of periodontal disease [18], a stronger predictor of tooth loss. Moreover, recent studies have shown plausible explanations on how the oral microbiota, especially periodontal disease, might play an important role in systemic health [36] and Alzheimer's disease [37]. One previous investigation has shown a dependent association of multimorbidity and edentulism later in life [28], but the impact on functional dentition was not well established. During the life course, dementia has been associated to tooth loss through three different mechanisms: nutritional status, occlusal contacts and inflammation [20]. One possible explanation could be that chronic periodontitis could result in tooth loss, but not before the inflammation has affected the central nervous system, impairing cognition. However, one proposed explanation is that people with better childhood cognitive function have better oral health and access to routine dental care as they go through life, losing fewer teeth along the life course. They are also much more likely to have a better cognitive function later in life [20]. To the authors' knowledge, this is the largest observational study using nationally representative data from Brazil to investigate the association of multimorbidity with tooth loss severity. 
Table 2 Prevalence and weighted proportions of morbidities in Brazilian adults and older adults. The National Health Survey, 2019

\begin{tabular}{|c|c|c|c|c|c|c|c|}
\hline \multicolumn{4}{|l|}{ Adults (18-59 years) } & \multicolumn{4}{|l|}{ Older-Adults (60 years and over) } \\
\hline \multirow[t]{2}{*}{ Multimorbidity } & $n=65,803$ & $\%$ & $\begin{array}{l}\text { Associated } \\
\text { morbidities }\end{array}$ & Morbidities & $n=22,728$ & $\%$ & $\begin{array}{l}\text { Associated } \\
\text { morbidities }\end{array}$ \\
\hline & & & mean & & & & mean \\
\hline \multicolumn{4}{|l|}{ Back problems } & \multicolumn{4}{|l|}{ Hypertension } \\
\hline yes & 12,414 & 19.0 & 2.09 & yes & 12,428 & 56.0 & 2.35 \\
\hline \multicolumn{4}{|l|}{ Hypertension } & \multicolumn{4}{|l|}{ Back problems } \\
\hline yes & 11,391 & 17.0 & 2.14 & yes & 6617 & 31.1 & 2.78 \\
\hline \multicolumn{4}{|l|}{ Depression } & \multicolumn{4}{|l|}{ Diabetes } \\
\hline yes & 5876 & 9.8 & 2.64 & yes & 4305 & 20.3 & 2.83 \\
\hline \multicolumn{4}{|c|}{$\begin{array}{l}\text { Mental problems (schizophrenia, bipolar disorder, dementia and } \\
\text { related) }\end{array}$} & \multicolumn{4}{|l|}{ Arthritis or rheumatism } \\
\hline yes & 3933 & 7.0 & 2.57 & yes & 4025 & 18.2 & 3.12 \\
\hline \multicolumn{4}{|l|}{ Asthma } & \multicolumn{4}{|l|}{ Heart problem } \\
\hline yes & 3311 & 5.5 & 2.2 & yes & 2724 & 13 & 3.47 \\
\hline \multicolumn{4}{|l|}{ Arthritis or rheumatism } & \multicolumn{4}{|l|}{ Depression } \\
\hline yes & 3174 & 4.6 & 2.92 & yes & 2366 & 11.8 & 3.59 \\
\hline \multicolumn{4}{|l|}{ Diabetes } & \multicolumn{4}{|l|}{ Cancer } \\
\hline yes & 3053 & 4.7 & 2.53 & yes & 1420 & 6,7 & 3.14 \\
\hline \multicolumn{4}{|l|}{ Heart problem } & \multicolumn{4}{|l|}{ Stroke } \\
\hline yes & 1987 & 3.1 & 3.04 & yes & 1271 & 5,6 & 3.47 \\
\hline \multicolumn{4}{|c|}{ Work-related musculoskeletal disorder } & \multicolumn{4}{|c|}{$\begin{array}{l}\text { Mental problems (schizophrenia, bipolar disorder, dementia and } \\
\text { related) }\end{array}$} \\
\hline yes & 1350 & 2.6 & 2.73 & yes & 859 & 4,7 & 3.87 \\
\hline \multicolumn{4}{|l|}{ Cancer } & \multicolumn{4}{|l|}{ Asthma } \\
\hline yes & 894 & 1.4 & 2.51 & yes & 983 & 4,6 & 3.58 \\
\hline \multicolumn{4}{|c|}{ COPD: chronic obstructive pulmonary disease } & \multicolumn{4}{|c|}{ COPD: chronic obstructive pulmonary disease } \\
\hline yes & 671 & 1.3 & 2,93 & yes & 587 & 2,9 & 4 \\
\hline \multicolumn{4}{|l|}{ chronic kidney disease } & \multicolumn{4}{|l|}{ chronic kidney disease } \\
\hline yes & 751 & 1.2 & 2.9 & yes & 529 & 2,6 & 3.92 \\
\hline Stroke & & & & work-related musculoskeletal diso & & & \\
\hline yes & 703 & 1.0 & 3.1 & yes & 360 & 2,2 & 3.72 \\
\hline Main dyad combinations & & & & Main dyad combinations & & & \\
\hline Back problems + Hypertension & 3235 & 5.2 & 3.3 & Hypertension + Back problems & 4082 & 20.0 & 3.5 \\
\hline Back problems + Depression & 2133 & 3.7 & 3.7 & Hypertension + Diabetes & 3169 & 14.8 & 3.7 \\
\hline Hypertension + Depression & 1850 & 3.0 & 3.8 & Back problems + Diabetes & 1296 & 6.7 & 4.1 \\
\hline Main Triad combinations & & & & Main Triad combinations & & & \\
\hline $\begin{array}{l}\text { Back problems + Hypertension+ } \\
\text { Depression }\end{array}$ & 823 & 1.5 & 4.6 & $\begin{array}{l}\text { Hypertension+ Back problems + } \\
\text { Diabetes }\end{array}$ & 1022 & 5.2 & 4.4 \\
\hline $\begin{array}{l}\text { Back problems + Hypertension+ } \\
\text { Mental problems }\end{array}$ & 443 & 0.8 & 4.6 & $\begin{array}{l}\text { Hypertension+ Back problems + } \\
\text { Arthritis }\end{array}$ & 1426 & 7.4 & 4.3 \\
\hline $\begin{array}{l}\text { Back problems + Hypertension+ } \\
\text { Asma }\end{array}$ & 287 & 0.5 & 4.9 & $\begin{array}{l}\text { Hypertension+ Back problems + } \\
\text { Heart problem }\end{array}$ & 840 & 4.5 & 4.7 \\
\hline
\end{tabular}

The adequate management of individuals with multimorbidity is a complex challenge and requires good planning and articulation of actions from the Brazilian Unified Health System (SUS) to meet this demand and special attention for oral health teams to prevent tooth loss in adults and older adults. In our investigation, multimorbidity was an independent associated factor with important levels of tooth loss (functional dentition and severe tooth loss) that are important indicators for public and global health. Addressing this issue will take more than the traditional approach, which radical reforms should accompany oral health systems and 
Table 3 Logistic regression coefficients for the association of tooth loss and multimorbidity in Brazilian older adults ( $n=22,728)$. The Brazilian National Health Survey, 2019

\begin{tabular}{|c|c|c|c|c|}
\hline \multirow[t]{3}{*}{ Multimorbidity } & \multicolumn{2}{|c|}{ Presence of Functional Dentition } & \multicolumn{2}{|c|}{ Severe tooth Loss } \\
\hline & Unadjusted & Adjusted $^{a}$ & Unadjusted & Adjusted $^{\mathrm{a}}$ \\
\hline & OR $(95 \% \mathrm{Cl})$ & OR $(95 \% \mathrm{Cl})$ & OR $(95 \% \mathrm{Cl})$ & OR $(95 \% \mathrm{Cl})$ \\
\hline no & 1 & 1 & 1 & 1 \\
\hline multimorbidity $\geq 2$ & $0.68(0.62 ; 0.72)$ & $0.77(0.70 ; 0.85)$ & $1.37(1.26 ; 1.49)$ & $1.17(1.06 ; 1.29)$ \\
\hline no & 1 & 1 & 1 & 1 \\
\hline multimorbidity $\geq 3$ & $0.66(0.60 ; 0.74)$ & $0.76(0.68 ; 0.86)$ & $1.39(1.26 ; 1.55)$ & $1.18(1.05 ; 1.32)$ \\
\hline
\end{tabular}

${ }^{a}$ Adjusted for sex, race, income, schooling, age groups, geographic region and smoking status

Table 4 Logistic regression coefficients for the association of levels of tooth loss and multimorbidity in Brazilian adults $(n=65,803)$. The Brazilian National Health Survey, 2019

\begin{tabular}{|c|c|c|c|c|}
\hline \multirow[t]{3}{*}{ Multimorbidity } & \multicolumn{2}{|c|}{ Presence of Functional Dentition } & \multicolumn{2}{|c|}{ Severe tooth Loss } \\
\hline & Unadjusted & Adjusted $^{a}$ & Unadjusted & Adjusted $^{\mathrm{a}}$ \\
\hline & OR $(95 \% \mathrm{Cl})$ & OR $(95 \% \mathrm{Cl})$ & OR $(95 \% \mathrm{Cl})$ & OR $(95 \% \mathrm{Cl})$ \\
\hline no ( 0 or 1 morbidity) & 1 & 1 & 1 & 1 \\
\hline multimorbidity $\geq 2$ & $0.34(0.31 ; 0.38)$ & $0.67(0.60 ; 0.75)$ & $2.80(2.50 ; 3.11)$ & $1.32(1.17 ; 1.49)$ \\
\hline no ( 0 or 1 morbidity) & 1 & 1 & 1 & 1 \\
\hline multimorbidity $\geq 3$ & $0.28(0.24 ; 0.31)$ & $0.61(0.52 ; 0.70)$ & $3.39(2.96 ; 3.90$ & $1.42(1.22 ; 1.66)$ \\
\hline
\end{tabular}

${ }^{\text {a }}$ Adjusted for sex, race, income, schooling, age, geographic region and smoking status

multidisciplinary teamwork [38]. An earlier diagnosis of multimorbidity (in adulthood) should be adopted since our investigation showed that adults with multimorbidity had higher chance of having tooth loss adjusted for the main social determinants of health [29]. The Brazilian Unified Health System should focus on promoting oral health behaviours such as toothbrushing twice or more times a day and the use of dental floss in these individuals. Most people with no multimorbidity (95.4\%) brushed their teeth twice or more and $65 \%$ declared that they used dental floss compared to $93.3 \%$ of individuals with multimorbidity $(\geq 2)$ who brushed their teeth twice or more and only $55 \%$ reported the use of dental floss. This difference between the groups was significant. Causal associations between amenable risk factors and noncommunicable diseases (NCDs), a large proportion of the multimorbidity burden, are well established [21]. However, it is necessary to include oral health in this agenda, as it shares the same risk factors. Oral health has been neglected globally [39] and should be included in the political agenda [3], especially on upstream oral health policies like the sugar tax [39].

An increase in preventive dental check-ups could explain a large share in tooth loss between different racial groups in older adults [32] and could be a potential pathway to integrative care with other professionals in the Family Health Strategy program to address multimorbidity. Although the number of dentists in Brazil is high, they are not equally distributed across the five large geographic regions and across private and public sectors [40]. This could cause barriers to dental care access in the country, especially for those who need public services, i.e., the poorest individuals. In Brazil, between 2007 and 2014, there was no significant increase in the number of dentists working in general practice in the public sector [40]. On the other hand, in private practice, there was an average increase of $24.5 \%$. This extensive discrepancy results in severe barriers to preventive dental services of the public sector users compromising the oral health of those who need it the most, i.e., the poorest, with the lowest level of education, non-white and individuals at higher risk for multimorbidity and tooth loss. For example, in 2013, data from the Brazilian National Health Survey have showed that, among individuals aged 18 or older, $11 \%$ were edentulous and $23 \%$ had fewer than 20 remaining teeth [30]. In the 2019 Survey, in the same age group, $10.3 \%$ were edentulous and $21.3 \%$ did not have 20 remaining teeth. The similar parameters of 2013 and 2019 could be associated by the limited access to the public health system as explained previously [40].

This study has some strengths and limitations that should be acknowledged. A key strength was the use of 
a nationally representative sample of Brazilian adults and older adults. The self-reported nature of tooth loss assessment may lead to information bias. Although clinical data regarding tooth loss might have strengthened our findings, previous research has shown a good concordance between self-reported tooth loss and clinical evaluation in national surveys [41]. Moreover, we used two definitions of tooth loss used internationally for comparison between populations. It was not also possible to establish whether tooth loss and occlusion, an essential predictor of maintaining masticatory functions and quality of life. The definition of multimorbidity is complex and vary across different studies and countries, and it is another limitation. However, we used two different classifications for multimorbidity (with the combination of 2 or 3 chronic diseases) and have conducted a sensitivity analysis to overcome this issue. For example, self-reported hypertension is a commonly used condition to measure multimorbidity [42]. Nevertheless, it is considered to be a risk factor for other non-communicable chronic diseases [43]. We, therefore, carried out an additional analysis, excluding hypertension, and confirmed our findings. We have also investigated the five Brazilian geographic regions to infer the place of residence, an important area-level characteristic. Our findings confirmed existing arealevel differences in the country that require further investigation, especially considering other variables such as health services coverage, nutritional statuses, frailty and access to health services. Another limitation of our study is its cross-sectional design that may not allow to establish a temporal relationship between exposures and outcomes. Our findings clearly showed the association of presence of multimorbidity with functional dentition and severe tooth loss. However, tooth loss as a longitudinal observation was not tested. Specifying the role of potential pathways by which tooth loss-related mortality is mediated by systemic inflammation and nutritional status will potentially increase the importance of dental treatment for general health [44]. Finally, the lack of data on eyes diseases such as cataracts and high cholesterol, conditions commonly used in international multimorbidity studies [35], may have resulted in underestimating multimorbidity in the present study.

In conclusion, adults and older adults with multimorbidity are more likely to have severe tooth loss and less likely to have functional dentition. Therefore, our findings reinforce the importance of the Family Health Strategy of the Brazilian Unified Health Service to identify those individuals living with multimorbidity to tackle its adverse effects on oral health. Our study also highlights the importance of including oral health on the non-communicable diseases burden agenda.

\section{Supplementary Information}

The online version contains supplementary material available at https://doi. org/10.1186/s12889-021-12392-2.

Additional file 1: Appendix 1. Logistic regression coefficients for the association of tooth loss and multimorbidity (excluding hypertension) in Brazilian older adults. The Brazilian National Health Survey, 2019. Appendix 2. Logistic regression coefficients for the association of levels of tooth loss and multimorbidity (excluding hypertension) in Brazilian adults. The Brazilian National Health Survey, 2019.

\section{Acknowledgements}

This study was partially financed by the Federal University of Mato Grosso do Sul (UFMS).

All methods were carried out in accordance with relevant guidelines and regulations.

\section{Authors' contributions}

RAB contributed to the conception, design, performed all statistical analyses, data interpretation, drafted and critically revised the manuscript. AMC contributed to the conception, data interpretation, drafted and critically revised the manuscript. CO contributed to the conception, data interpretation, drafted and critically revised the manuscript. All authors revised the final version of the manuscript, gave their final approval and agreed to be accountable for all aspects of the work.

\section{Funding}

Dr. Cesar de Oliveira is supported by the Economic and Social Research Council (ESRC) (grant: ES/TT008822/11).

\section{Availability of data and materials}

The data that support the findings of this study are openly available in [Brazilian Institute of Geography and Statistics (IBGE)] at [https://www.ibge.gov.br/ estatisticas/downloads-estatisticas.html].

\section{Declarations}

Ethics approval and consent to participate

The Brazilian Committee approved the survey protocol on Ethics in Human Research (protocol number 3.529.376). Informed consent was obtained from all subjects.

\section{Consent for publication}

'Not Applicable'.

\section{Competing interests}

The authors declare no conflict of interest.

\section{Author details}

${ }^{1}$ School of Dentistry, Federal University of Mato Grosso do Sul, Campo Grande, Brazil. ${ }^{2}$ Department of Public Health, Federal University of Santa Catarina,

Florianópolis, Brazil. ${ }^{3}$ Department of Epidemiology \& Public Health, University College of London, London, UK.

Received: 18 September 2021 Accepted: 7 December 2021

Published online: 20 December 2021

\section{References}

1. Marcenes W, Kassebaum NJ, Bernabe E, Flaxman A, Naghavi M, Lopez A, et al. Global burden of Oral conditions in 1990-2010: a systematic analysis. J Dent Res. 2013;92(7):592-7. 
2. Haworth S, Shungin D, Kwak SY, Kim HY, West NX, Thomas SJ, et al. Tooth loss is a complex measure of oral disease: determinants and methodological considerations. Community Dent Oral Epidemiol. 2018;46(6):555-62.

3. Bernabe E, Marcenes W, Hernandez CR, Bailey J, Abreu LG, Alipour V, et al. Global, regional, and National Levels and trends in burden of Oral conditions from 1990 to 2017: a systematic analysis for the global burden of disease 2017 study. J Dent Res. 2020;99(4):362-73.

4. Gabel F, Jürges H, Kruk KE, Listl S. Gain a child, lose a tooth? Using natural experiments to distinguish between fact and fiction. J Epidemiol Community Health. 2018;72(6):552-6.

5. Felton DA. Complete Edentulism and comorbid diseases: an update. J Prosthodont. 2016;25(1):5-20.

6. Toniazzo MP, Amorim PS, Muniz F, Weidlich P. Relationship of nutritional status and oral health in elderly: systematic review with meta-analysis. Clin Nutr. 2018;37(3):824-30.

7. Nascimento GG, Leite FR, Conceicao DA, Ferrua CP, Singh A, Demarco FF. Is there a relationship between obesity and tooth loss and edentulism? A systematic review and meta-analysis. Obes Rev. 2016;17(7):587-98.

8. Dietrich T, Webb I, Stenhouse L, Pattni A, Ready D, Wanyonyi KL, et al. Evidence summary: the relationship between oral and cardiovascular disease. Br Dent J. 2017:222(5):381-5.

9. Shin HS. Association between the number of teeth and hypertension in a study based on 13,561 participants. J Periodontol. 2018;89(4):397-406

10. Patel MH, Kumar JV, Moss ME. Diabetes and tooth loss: an analysis of data from the National Health and nutrition examination survey, 2003-2004. J Am Dent Assoc. 2013;144(5):478-85.

11. Maisonneuve P, Amar S, Lowenfels AB. Periodontal disease, edentulism, and pancreatic cancer: a meta-analysis. Ann Oncol. 2017;28(5):985-95.

12. Wang RS, Hu XY, Gu WJ, Hu Z, Wei B. Tooth loss and risk of head and neck cancer: a meta-analysis. PLoS One. 2013;8(8):e71122.

13. Peng J, Song J, Han J, Chen Z, Yin X, Zhu J. The relationship between tooth loss and mortality from all causes, cardiovascular diseases, and coronary heart disease in the general population: systematic review and dose-response meta-analysis of prospective cohort studies. Biosci Rep. 2019;39(1):BSR20181773.

14. Bomfim RA, Frias AC, Cascaes AM, Pereira AC. Functional dentition and associated factors in Brazilian elderly people: a multilevel generalised structural equation modelling approach. Gerodontology. 2018;35(4):350-8.

15. Petersen P, Kwan S. The 7(th) WHO global conference on health promotion - towards integration of oral health (Nairobi, Kenya 2009). Community Dent Health. 2010;27(2):129-36.

16. Kassebaum NJ, Bernabé E, Dahiya M, Bhandari B, Murray CJ, Marcenes W. Global burden of severe tooth loss: a systematic review and Meta-analysis. J Dent Res. 2014;93(7 Suppl):20S-8S.

17. Graves DT, Corrêa JD, Silva TA. The Oral microbiota is modified by systemic diseases. J Dent Res. 2019;98(2):148-56.

18. Jepsen S, Caton JG, Albandar JM, Bissada NF, Bouchard P, Cortellini P, et al. Periodontal manifestations of systemic diseases and developmental and acquired conditions: consensus report of workgroup 3 of the 2017 world workshop on the classification of periodontal and Peri-implant diseases and conditions. J Clin Periodontol. 2018:45(Suppl 20):S219-S29.

19. de Smit MJ, Westra J, Brouwer E, Janssen KM, Vissink A, van Winkelhoff AJ. Periodontitis and rheumatoid arthritis: what do we know? J Periodontol. 2015;86(9):1013-9.

20. Thomson WM, Barak Y. Tooth loss and dementia: a critical examination. J Dent Res. 2021;100(3):226-31.

21. Hajat C, Stein E. The global burden of multiple chronic conditions: a narrative review. Prev Med Rep. 2018;12:284-93.

22. Dong G, Feng J, Sun F, Chen J, Zhao XM. A global overview of genetically interpretable multimorbidities among common diseases in the UK biobank. Genome Med. 2021;13(1):110.

23. Head A, Fleming K, Kypridemos C, Pearson-Stuttard J, O'Flaherty M. Multimorbidity: the case for prevention. J Epidemiol Community Health. 2021;75(3):242-4.

24. Nunes BP, Batista SRR, Andrade FB, Souza Junior PRB, Lima-Costa MF, Facchini LA. Multimorbidity: The Brazilian Longitudinal Study of Aging (ELSI-Brazil). Rev Saude Publica. 2018;52(Suppl 2):10s.
25. Harrison C, Britt H, Miller G, Henderson J. Examining different measures of multimorbidity, using a large prospective cross-sectional study in Australian general practice. BMJ Open. 2014;4(7):e004694

26. Cassell A, Edwards D, Harshfield A, Rhodes K, Brimicombe J, Payne R, et al. The epidemiology of multimorbidity in primary care: a retrospective cohort study. Br J Gen Pract. 2018;68(669):e245-e51.

27. Ward BW, Schiller JS, Goodman RA. Multiple chronic conditions among US adults: a 2012 update. Prev Chronic Dis. 2014;11:E62.

28. Islas-Granillo H, Borges-Yañez SA, Navarrete-Hernández JJ, Veras-Hernández MA, Casanova-Rosado JF, Minaya-Sánchez M, et al. Indicators of oral health in older adults with and without the presence of multimorbidity: a cross-sectional study. Clin Interv Aging. 2019;14:219-24.

29. Watt RG. Social determinants of oral health inequalities: implications for action. Community Dent Oral Epidemiol. 2012;40(Suppl 2):44-8.

30. Nico LS, Andrade SS, Malta DC, Pucca Júnior GA, Peres MA. Self-reported oral health in the Brazilian adult population: results of the 2013 National Health Survey. Cien Saude Colet. 2016;21(2):389-98.

31. Stopa SR, Szwarcwald CL, Oliveira MM, Gouvea ECDP, Vieira MLFP, Freitas MPS, et al. National Health Survey 2019: history, methods and perspectives. Epidemiol Serv Saude. 2020;29(5):e2020315.

32. Bomfim RA, Schneider IJC, de Andrade FB, Lima-Costa MF, Corrêa VP, Frazão P, et al. Racial inequities in tooth loss among older Brazilian adults: a decomposition analysis. Community Dent Oral Epidemiol. 2021;49(2):119-27.

33. von Elm E, Altman DG, Egger M, Pocock SJ, Gotzsche PC, Vandenbroucke $J P$, et al. The strengthening the reporting of observational studies in epidemiology (STROBE) statement: guidelines for reporting observational studies. Int J Surg. 2014;12(12):1495-9.

34. Wiener RC, Shen C, Findley PA, Sambamoorthi U, Tan X. The association between diabetes mellitus, sugar-sweetened beverages, and tooth loss in adults: evidence from 18 states. J Am Dent Assoc (1939). 2017;148(7):500-9.e4

35. Garin N, Koyanagi A, Chatterji S, Tyrovolas S, Olaya B, Leonardi M, et al. Global multimorbidity patterns: a cross-sectional, population-based, multi-country study. J Gerontol A Biol Sci Med Sci. 2016;71(2):205-14.

36. Falcao A, Bullón P. A review of the influence of periodontal treatment in systemic diseases. Periodontol 2000. 2019;79(1):117-28.

37. Schwahn C, Frenzel S, Holtfreter B, Van der Auwera S, Pink C, Bülow R, Friedrich N, Völzke H, Biffar R, Kocher T, Grabe HJ; Alzheimer's Disease Neuroimaging Initiative. Effect of periodontal treatment on preclinical Alzheimer's disease-Results of a trial emulation approach. Alzheimers Dement. 2021. https://doi.org/10.1002/alz.12378. Epub ahead of print.

38. Watt RG, Serban S. Multimorbidity: a challenge and opportunity for the dental profession. Br Dent J. 2020;229(5):282-6.

39. Watt RG, Daly B, Allison P, Macpherson LMD, Venturelli R, Listl S, et al. Ending the neglect of global oral health: time for radical action. Lancet. 2019;394(10194):261-72.

40. Cascaes AM, Dotto L, Bomfim RA. Trends in the dental surgeon workforce in Brazil 2007-2014: a time series study using data from the National Registry of Health Services. Epidemiol Serv Saude. 2018;27(1):e201723615. https://doi.org/10.5123/S1679-49742018000100015.

41. Margozzini P, Berríos R, Cantarutti C, Veliz C, Ortuno D. Validity of the self-reported number of teeth in Chilean adults. BMC Oral Health. 2019;19(1):99.

42. Fortin M, Stewart M, Poitras ME, Almirall J, Maddocks H. A systematic review of prevalence studies on multimorbidity: toward a more uniform methodology. Ann Fam Med. 2012;10(2):142-51.

43. Collaboration WHO. Cardiovascular disease, chronic kidney disease, and diabetes mortality burden of cardiometabolic risk factors from 1980 to 2010: a comparative risk assessment. Lancet Diabetes Endocrinol. 2014;2(8):634-47.

44. Polzer I, Schwahn C, Völzke H, Mundt T, Biffar R. The association of tooth loss with all-cause and circulatory mortality. Is there a benefit of replaced teeth? A systematic review and meta-analysis. Clin Oral Investig. 2012;16(2):333-51.

\section{Publisher's Note}

Springer Nature remains neutral with regard to jurisdictional claims in published maps and institutional affiliations. 